\title{
Da diversidade na passagem para a quinta série do ensino fundamental
}

\author{
Diversity in the transition from forth to fifth \\ grade in grade school
}

\author{
Laíssa ESCHILETTI PRATI \\ Marisa Faermann EIZIRIK
}

\begin{abstract}
Resumo
Este estudo investiga a constituição de subjetividades da diversidade de práticas que surgem na passagem da quarta para a quinta série do ensino fundamental. Acompanharam-se duas turmas de quarta série e três turmas de quinta série em duas escolas públicas da rede estadual de ensino de Porto Alegre. As vivências de cerca de 150 alunos, 50 pais e 25 professores que convivem nesse momento da escolaridade foram acompanhadas durante um ano. A realidade escolar é compreendida como um poliedro de faces complementares e ambivalentes em interação, possibilitando a criação de um campo polifônico. A passagem da quarta para a quinta série do ensino fundamental surge como um momento emblemático que envolve mudanças principalmente nas funções que esses personagens assumem. Nesse espaço surgem forças multiformes que impulsionam novas práticas para a constituição de subjetividades.
\end{abstract}

Palavras-chave: diversidade; ensino fundamental; transição.

\begin{abstract}
This study investigates the subjectivity constitution through the diverse practices of the passage from elementary to high school. Two fourth grade classes from the elementary school, and three first grade classes from high school from two public schools in Porto Alegre, RS had been observed. Fifty fathers, about 150 students and 25 teachers, all of them involved in this special process, have contributed with their experiences for one whole year. The school reality is considered a complementary and ambivalent faces of a polyhedron in interaction, that allows the polyphonic practices creation. The elementary to high school passage arises an emblematic moment that involves important changes on the characters' roles. At this moment, multiform straights impel new practices for the subjectivity constitution.
\end{abstract}

Key words: diversity; elementaryeducation; transition.

Este estudo tem o objetivo de rastrear os efeitos das práticas que constituem os sujeitos na passagem da quarta para a quinta série do ensino fundamental. A intenção de capturar práticas que se engendram no ingresso em uma outra estrutura de funcionamento didático-pedagógica possibilita o acesso a um momento visibilizador da complexidade do mundo escolar. Foi necessário escolher algumas estratégias de contato com a multiplicidade desse momento específico, apresentado pela literatura como um espaço de intran-

$\boldsymbol{\nabla} \mathbf{\nabla} \boldsymbol{\nabla}$

1 Psicóloga, Mestre. Porto Alegre, RS, Brasil.

2 Professora Doutora, Programa de Pós-Graduação em Psicologia Social e Institucional, Universidade Federal do Rio Grande do Sul. Rua Ramiro Barcelos, 2600, Térreo, Santana, 90035-007, Porto Alegre, RS, Brasil. Correspondência para/Correspondence to: M.F. ELZIRIK. E-mail:<meizerik.ez@ terra.com.br>. 
qüilidade e descontinuidade (Leite, 1993; Neves \& Almeida, 1996; Rangel, 2001; Rosa \& Proença, 2003).

Esse texto, portanto, apresenta uma aproximação com a diversidade que se reflete nas subjetividades dos que convivem nesse espaço escolar. Entendendo subjetividade como um processo provisório, busca-se capturar a relação consigo mesmo que se estabelece por meio de uma série de procedimentos propostos e prescritos aos indivíduos em todas as civilizações, para fixar, manter ou transformar sua identidade (Eizirik, 1997). Professores, pais e alunos interferem no processo de construção de subjetividade que ocorre no ambiente escolar. Ao investigar as relações entre esses grupos, torna-se evidente a presença de múltiplos olhares e a impossibilidade de capturar todos os movimentos que aí se encadeiam. Na interação entre grupos distintos, percebe-se o acionamento de diversas forças que tensionam os fios que constituem o cotidiano escolar. O contato com o dia-a-dia escolar permite acompanhar uma vida dinâmica, em tensão.

Partiu-se em busca do contato com fluxos, alterações e possibilidades que surgem nessa passagem. A tentativa de capturar as práticas que compõem esse momento específico da escolaridade permitiu o acesso ao poli. Esse termo tem sua origem no grego - polýs -, e significa"muito". É utilizado, neste texto, como referência à multiplicidade de movimentos, sentidos e sons que tecem a complexidade do mundo escolar. A passagem da quarta para a quinta série serviu como um visibilizador das práticas que se articulam e se sobrepõem ao longo de toda a dinâmica escolar.

As práticas são entendidas como tendo características polimórficas, polifônicas e polissêmicas. $\mathrm{O}$ polimorfismo indica a capacidade de os jogos de poder e saber apresentarem-se sob muitas formas, contendo os mesmos elementos em sua composição. A polifonia, apresentando várias melodias independentes, marca os fluxos, indica ritmos, define espaços e possibilidades, construindo a complexidade escolar. E a polissemia permite o acesso aos discursos que se engendram em redes de significados diversos e salienta que uma palavra carrega várias possibilidades de interpretação, de acordo com o momento no qual irrompe.

Múltiplos sentidos, sons e formas constroem um fluxo que atravessa e liga a quarta e a quinta série. Quando as práticas nessa passagem são captadas por meio dos seus vários sentidos e intensidades surge uma realidade multifacetada, um espaço de combate e tensão, caracterizado por lutas e por uma vivência escolar com muitas faces.

Com apoio nas idéias de Foucault (2003), entende-se esse momento de passagem como "um 'poliedro de inteligibilidade', cujo número de faces não é previamente definido e nunca pode ser considerado como legitimamente concluído" (p.340). É preciso enfatizar que quanto mais se decompõe a passagem da quarta para a quinta série mais é possível ver as conexões que aí se constituem.

A possibilidade de decompor e recompor a realidade escolar indica que o "poli"pode ser identificado nas formas de apreender a realidade escolar. O processo de compreender essas múltiplas faces encadeia, transforma e cria diversas possibilidades de entendimento da passagem e das práticas que lá se engendram. Foi preciso escolher leituras, selecionar dados e construir histórias. Outras leituras são possíveis. Essa é a riqueza de um poliedro: sempre desencadear outras possibilidades de compreensão da realidade.

Nesse trabalho, buscou-se uma escola onde a complexidade de sons, movimentos, sentimentos, olhares e expectativas se articulam e constituem a vida escolar. Tempos e espaços, diferentes sentidos e direções produzem os jogos que são vivenciados no cotidiano da quarta e quinta séries. Optou-se, então, por fazer alguns pinçamentos sobre essa complexidade. Na pinça se encontra uma prática que não ocorre sozinha. Faz-se um zoom para capturar um movimento que ocorre aos turbilhões. Um detalhe da complexidade será ampliado para que a riqueza do movimento seja capturada. 0 foco está em momentos que se relacionam com outros e que possibilitam diversas leituras. Pára-se o tempo para salientar um processo que só se percebe estando conectado com o fluxo presente nas práticas escolares.

Observando os "lugares de encadeamento do que se diz e do que se faz, das regras que se impõem e das razões que se dão" presentes nas séries investigadas, pode-se identificar o surgimento de práticas diferentes na vivência da passagem entre essas (Foucault, 2003, p.338). Eizirik (2001) apresenta a escola como um espaço de trocas afetivas e intelectuais, um espaço de socialização, desenvolvimento de potencialidades e de aprendizagem de regras culturais. Na passagem da 
quarta para a quinta série evidenciam-se práticas que permitem o desenvolvimento de recursos pessoais até então não acionados. Elementos novos e antigos se rearranjam, compondo uma nova paisagem no dia-a-dia escolar.

Com a intenção de compreender por que a passagem da quarta para a quinta série é apresentada pela literatura como"um momento de dificuldades, não alegrias, e fragilidade no desempenho escolar" (Rangel, 2001, p.64), tentou-se capturar os elementos que aí se articulam, já que são capazes de acionar novas práticas em professores, pais e alunos. Soma-se a isso a sensação descrita pelos alunos, professores e pais de que algo diferente irá acontecer a partir da quinta série.

O que muda nessa passagem? Pais, professores e alunos se fazem presentes, tanto na quarta quanto na quinta série. A instituição escolar permanece a mesma. Porém a passagem da quarta para a quinta série se configura como um momento no qual novos elementos complexificam as práticas adotadas por professores, pais e alunos. A passagem é descrita como uma época de transformações e desafios, especialmente para o aluno. Segundo Bossa (2000), entrar para a quinta série, ao mesmo tempo em que simboliza o desejo de crescer, de lutar por uma nova identidade e expectativa social, faz com que o aluno tenha que lidar com a dor que esse crescimento pode trazer. Embasando-se nas informações dadas pelos professores e pais de alunos da quarta série, cria-se uma atmosfera de preocupações em torno da passagem da quarta para a quinta série. Pais, professores e alunos acabam precisando encontrar outras formas de conviver. Esse movimento permite a participação diferenciada, no seu cotidiano, de todos os segmentos que a compõem (Neves \& Almeida, 1996).

\section{Método}

Esse estudo foi realizado por meio de observação participante (Taylor \& Rogdan, 1996) do cotidiano de duas escolas da rede estadual ${ }^{3}$ de ensino de Porto Alegre que estão diretamente relacionadas com a passagem da quarta para a quinta série. Ao longo de um ano, somaram-se 220 horas de observação, conversas formais e informais e participação em eventos e reuniões. Nesse período, o objetivo principal foi manter o contato com os diversos personagens que se relacionam com esse momento da vida escolar (alunos, professores, pais, diretores, supervisores e orientadores educacionais). Diversos espaços foram acompanhados: salas de aula, salas dos professores, pátio e corredores. Durante esse período de contato com a escola buscou-se responder a uma pergunta principal: quais os efeitos das práticas que constituem os sujeitos na passagem da quarta para a quinta série do ensino fundamental?

Um total de 150 alunos (com idade variando entre 9 e 14 anos), 50 pais e 25 professores (de quarta e quinta séries) compuseram os participantes desse estudo. Duas turmas de quarta e três turmas de quinta séries foram os focos principais das observações nas quais as práticas foram observadas e compreendidas no seu contexto. Optou-se por não construir categorias de análise, mas escolher frases-chave que indicam alguns fios constituintes da realidade escolar. São práticas que irrompem na quarta e na quinta série, porém assumem significados diferentes conforme o momento em que surgem. Mensagens contraditórias puderam ser percebidas convivendo nos mesmos espaços, salientando ainda mais a complexidade da vida escolar.

\section{Procedimentos}

Após o período de coleta de dados e de sua organização, buscou-se encontrar uma forma de lidar com os dados que permitisse o acesso à complexidade que enriquece o campo escolar. Construiu-se, portanto, um quadro com falas (caleidoscópio de práticas) que indicam algumas possibilidades de acesso ao poli que constitui a vida escolar: situações que se complementam, se contradizem e se fortalecem; falas de pais, professores, alunos e demais personagens escolares que permitem o acesso ao processo criador e inventivo que produz as subjetividades dos que convivem nesse momento escolar. Algumas frases apareceram apenas uma vez durante a coleta de dados, mas indicaram movimentos e possibilidades que compunham a passagem e por isso foram escolhidas. As próprias palavras

$\boldsymbol{\nabla} \boldsymbol{\nabla} \boldsymbol{\nabla}$

3 A rede municipal não se divide em séries. Está organizada em ciclos de aprendizagem, o que descaracteriza a passagem estudada. 
apresentadas no cotidiano escolar servem como fios condutores da análise que segue. Algumas falas foram aproximadas por indicarem o mesmo movimento, outras foram distanciadas por servirem de referência a outras possibilidades.

\section{Resultados}

Apresentam-se a seguir algumas linhas que constituem a complexidade do cotidiano escolar e falas e diálogos que criam um terreno flexível e fértil para a articulação de novos jogos e estratégias de subjetivação.

\section{"Será que a quinta série é mais difícil?"}

Já na quarta série se percebe uma preocupação com o que vai acontecer na série seguinte. Colocações como: "Será que a quinta série émais difícil?", feita por uma aluna ou "Eu me preocupo bastante com o que vai acontecer. Minha filha está na quarta e já fico pensando como vai ser o próximo ano", feita por uma mãe demonstram uma apreensão com relação ao ingresso na nova organização escolar. Os professores de quinta série também se mostram preocupados com os alunos dessa série, como indicado na frase: "Eu sou professora de área e não tenho a mínima visão de currículo. Eé difícil a gente enxergar a faixa etária deles e não sei se atendo as expectativas deles".

Os alunos de quarta série, quando conversam sobre a quinta, indicam sentimentos ambivalentes frente aos desafios que irão enfrentar. Frases desde "Eu estou louca que chegue a quinta série!" até "Vai ser muito ruim. Vai ter coisas novas e eu não vou saber." são ouvidas na quarta série. Viu-se a composição de um contínuo de expectativas relacionadas diretamente ao que é apresentado pelos discursos de professores, pais e outros alunos - que já tiveram contato com pessoas que convivem na quinta série. Falas de alunos referiam que ter vários professores e várias matérias iria exigir mais responsabilidade deles. Essa expectativa era confirmada, principalmente, pela falas dos professores da quarta série: "Pessoal, vou dar uma revisada bem rápida. Vocês têm que começar a se preparar para a quinta série! Na quinta não vaiser essa moleza! Vocês sabem muito bem disso!"’Também se ouviam frases como "Lá [na quinta série] não tem essa de ficar passando a mão por cima [do aluno] como no currículo".

\section{"Vir para escola a gente gosta, não gostamos de vir para a aula! É diferente, muito diferente!"}

Para os alunos de quarta série a escola é uma unidade (um espaço único). Vir para a aula e para a escola é a mesma coisa. Entretanto, os alunos de quinta série percebem a escola e a aula de maneiras distintas. Cada um desses espaços assume um significado próprio.

Até a quarta série, o aluno está sempre sendo cuidado pelo seu professor, que é o responsável por tudo que ele fizer. A situação descrita a seguir enfatiza essa vigilância constante dos alunos. Na sala de professores, eles comentavam o que tinha acontecido com duas alunas da quarta: "Deu o maior bafafá, ontem, com os pais. Duas meninas saíram do colégio na hora do recreio e ficaram matando aula na praça aqui perto! Deu a maior confusão!". Alguém, provavelmente a professora da turma, percebendo a ausência das meninas, procurou localizá-las e acionou os pais. Pais e professores conversaram sobre a atitude e combinaram as conseqüências diante do comportamento das alunas: suspensão de três dias.

Essa prática se modifica na quinta. Os alunos percebem que é possível ficar na escola sem um adulto responsável por eles. É bastante freqüente a combinação de encontrar amigos no turno inverso da aula ou permanecer na escola durante períodos vagos. Ao longo do ano, os espaços aula e escola passam a ser avaliados de formas distintas pelos alunos da quinta série. Vários deles diziam: "Vir para escola a gente gosta, não gostamos de vir para a aula! É diferente, muito diferente!". Ao perceberem claramente a possibilidade de não existir uma pessoa responsável por seus atos em todos os minutos, a escola passa a dar conta de outras expectativas que não só a de estar em sala de aula aprendendo. Uma professora de quinta série chegou a verbalizar: "Parece que eles vêm para um clube social, encontrar amigos".

\section{"Eles fazem qualquer coisa para ficar fora da sala de aula. Nós não. Nós temos que estudar!"}

A diferenciação entre o espaço da escola e o da sala de aula gera diferenças na forma como os alunos percebem as atividades propostas pelos professores. 
Como para os alunos da quarta todas as atividades que acontecem na escola fazem parte da aula, a aula de educação física e atividades fora da sala de aula são consideradas atividades livres. Um aluno da quarta, baseado em informações de alunos da quinta série, afirma: "Parece que todos jogam vôlei. A educação física é toda organizada, não é essa de largar a bola e cada um faz o que quer". Vários alunos, ainda na quarta série, se mostram preocupados, pois, ao perceberem que a educação física na quinta série é coordenada pelo professor, têm a impressão de não existir mais tempo no qual cada um possa agir de acordo com o que deseja. Seguindo a lógica criada pelos alunos da quarta série, na aula de educação física a sala de aula se transfere para o pátio e o professor coordena o espaço e define os ritmos. Os alunos seguem orientações e executam as atividades para aprender como se joga.

Esse sentimento muda ao se falar com os alunos da quinta série. Acredita-se que, por entenderem que podem circular na escola sem a tutela constante de um professor, os alunos de quinta série percebem que o professor tem controle sobre a sala de aula e sobre a aprendizagem. Nos outros espaços (pátio e corredor), os alunos têm maior autonomia. A fala de uma aluna de quinta série, enquanto observava um grupo da quarta série ensaiando para uma apresentação no dia das mães, evidencia essa compreensão: "Eles fazem qualquer coisa para ficar fora da sala de aula. Nós não. Nós temos que estudar!". Os alunos de quarta série sentiam-se em atividade de aula, mas os alunos de quinta entendiam isso como não aula. A diferença entre os espaços de pátio e sala de aula é ainda enfatizada pelas solicitações para ter aula no pátio que poucas vezes são atendidas pelos professores de quinta série. O espaço fora da sala de aula passa a ser, para os alunos de quinta série, um lugar onde se encontram amigos. Ao solicitarem aula na rua, sentem-se mais à vontade para conversar e agir de forma mais espontânea.

Raramente os professores de quinta série organizavam atividades fora da sala de aula, prática que acontecia bastante na quarta. Os professores de geografia e ciências organizaram um passeio para os alunos de quinta série: um filme que integrava esses conteúdos. Comentavam que as crianças não aproveitaram nada do filme, só conversavam, comiam e passeavam como se tivessem ido ao shopping.
Afirmaram se arrepender de fazer atividades desse tipo: "Tem que ficar em sala de aula mesmo!".

\section{"Quando a gente tiver cansado de um professor vem outro!"}

Durante toda a quarta série, era bastante enfatizado pelos professores que a existência de períodos poderia ser um fator que dificultasse a organização dos alunos. Os alunos, entretanto, conseguiam ver pontos positivos e negativos nessa prática. Baseados em experiências pessoais ou de colegas, os alunos de quarta série diziam: "Eu acho que eu não vou me acostumar. Por exemplo, se uma [professora] se chama de Carolina e a outra de Andréia. Eu vou acabar chamando a Andréia de Carolina. Tu vaiver só!" ou "Não vaiencher o saco. Quando a gente tiver cansado do professorvem outro. Ese ele nos mandar para a direção a gente pode ficar mais tempo na rua. Vamos pro pátio brincar".

A troca de períodos, de uma forma geral, era vista como um desafio a ser enfrentado pelos alunos. Os professores preocupavam-se com a dificuldade de organização do material se os alunos saíssem da sala na troca de períodos e organizaram-se para que isso não acontecesse. Um professor esperava em sala até a chegada do seguinte. O espaço para respirar, esperado por alguns alunos, era reduzido. Uma forma de romper com a regra era pedir para beber água ou ir ao banheiro. Muitos autorizavam a saída e os alunos tinham seus minutinhos de folga. Era, também, aí que os alunos tinham espaço para emprestar, ou pedir emprestado, material para amigos das outras turmas.

A preocupação com saber os nomes dos professores foi rapidamente substituída por saber qual a matéria desenvolvida por esse professor. Surgiram então "o soro [sic] de história" e "a sora de geografia". Os professores também escolhiam características dos alunos para identificá-los. Ao longo do ano, essa angústia foi diminuindo e os nomes foram sendo identificados.

\section{“Ninguém merece!"}

Essa frase foi ouvida na quarta e quinta série, dita por professores e alunos. O interessante foi perceber os diversos significados atribuídos a ela. Em alguns 
momentos, aproximava os envolvidos no discurso, em outros, afastava-os. Julgamentos ou risos a circundavam.

Uma vez que essa frase chamou atenção foi quando a professora de quarta série, após ter tirado um aluno de sala de aula, disse com tom de "não agüento mais estar aqui". O aluno havia desrespeitado sua ordem e "ninguém merece" aturar alunos que não seguem combinações. O aluno chegou a retrucar que "ninguém merece é ser injustiçado", mas essa fala não foi valorizada por colegas e pela professora.

Na segunda semana de aula da quinta série essa frase voltou a aparecer. A vice-diretora estava ocupando um período de matemática (já que a escola não tinha ainda professora responsável por essa matéria). No início do período, percebeu que os alunos não paravam de conversar e disse que não iria aturar se os alunos tivessem a mesma atitude que tiveram na aula anterior (quando gritavam para ela sair de sala). Afirmou que tinha conversado com a diretora e que chegaram à conclusão que "ninguém merece" passar por aquilo novamente.

Essa mesma frase também apareceu assumindo outros significados. Num outro momento, uma professora vinha rodeada de alunos no corredor entre a sala de aula e a sala dos professores. Conversavam sobre namorados e estratégias das meninas para saber o que os meninos andavam fazendo. Quando uma aluna estava quase "dependurada" no pescoço da professora, para falar ao seu ouvido, essa, sorrindo, disse: "Ninguém merece!". Alunos e professora riram e continuaram conversando até a porta da sala dos professores.

Numa outra oportunidade, uma aluna utilizou a mesma frase: a professora tentava fazer um grupo de alunos parar de conversar e se envolver com a atividade proposta. Após várias tentativas a menina disse: "Ninguém merece, nésora!".

\section{"Não acho que tu estás mostrando que tens condições de ir pra quinta"}

No final do ano, as professoras de quarta série mostravam-se preocupadas em preparar os alunos para a série seguinte. Elas apresentavam a quinta como uma série na qual os alunos seriam bastante cobrados por professores menos tolerantes e mais distantes do que elas. A preocupação estava em desenvolver os conteúdos considerados pré-requisitos para freqüentar a quinta. A forma de verificação mais utilizada era a prova - mesmo a denominando "trabalhinho"-, prática que se disseminaria na quinta série. Uma professora verbalizou: "Eu tenho um horror de coisas para corrigir! Tive que verificar como eles estão no conteúdo em função da quinta série".

Outra preocupação era preparar os alunos para acompanhar os ritmos dos diversos professores. Conversavam que teriam que estar preparados para entrar no ritmo de cada um - salientando que, no geral, seria mais rápido do que o da quarta série. O segundo semestre da quarta série pareceu ser fundamental para a preparação para a série seguinte. Qualquer aluno que não parecesse comprometido com as atividades acabava ouvindo frases do tipo: "Não acho que tu estás mostrando que tens condições de ir pra quinta".

\section{"Agora a professora é como uma mãe!"}

A partir dos inúmeros cuidados e alertas em relação à nova organização do ensino, os alunos acabam construindo a visão de que "Agora a professora é como uma mãe. Edepois não vai mais ser assim". Já começam a se preparar para lidar com professores que não estarão disponíveis para eles. Os professores de quinta série confirmam esse discurso por meio de colocações como: "Essa é uma grande diferença na quinta. Nós não temos tempo de sentar do lado de cada aluno para ajudá-los a fazer a atividade. Eles têm que ir sozinhos".

Muitos professores enfatizavam que "Aula nãoé lazer, é obrigação!". Indicavam que o espaço de sala de aula é o lugar onde os alunos devem estar disponíveis para aprender e não se envolver com conversas com os colegas sobre assuntos que não se relacionam diretamente com o que está sendo estudado. As professoras de quarta série muitas vezes perguntavam sobre as vidas particulares dos alunos, prática que aconteceu raramente na quinta série. Essa alteração nas práticas acaba tornando verdadeira a frase dita por professoras de quinta série: "O que é probleminha na quarta dobra de tamanho na quinta".

A diferença de expectativa entre esses dois grupos de professores faz com que os professores de quinta cobrem um maior comprometimento dos alunos. Isso dá a impressão de confirmar as colocações de que os professores de quinta série seriam mais 
exigentes. Com objetivos diferentes, os professores percebem-se lidando com um grupo imaturo, não preparado para a série. Frases como: "Tu dá uma virada para o quadro e dali a pouco tem um grupo batendo figurinha!" e "Eles são muito pequenos, e nós com outra cabeça querendo ir mais longe" demonstram que os professores não sentem que suas aulas prendem a atenção dos alunos ou não se sentem valorizados por eles.

\section{“Ele está sempre fazendo isso. Sempre matando aula, sora!"}

Um maior sentimento de liberdade, vivido pelos alunos no espaço escolar, acaba invadindo a sala de aula. Os alunos sugerem alterações para os professores e correm o risco de não serem atendidos. Já na primeira semana de aula, essas práticas podiam ser percebidas. Durante o segundo dia de aula de português, alguns alunos foram até a professora, dizendo: "Sora, espera! Não começa a aula ainda que faltam muitos colegas. Não escreve nada ainda!". A professora os tranqüilizou afirmando que daria tempo para os colegas chegarem, mas que eles já deveriam ir abrindo seu material e se organizando.

O espaço fora da aula parece ser mais valorizado pelos alunos da quinta série. Sentindo-se com maior autonomia, os alunos sentem-se, inclusive, com a possibilidade de optar por esse novo espaço. Surge a possibilidade de "matar" as aulas que não são consideradas importantes pelos alunos, como demonstra a situação a seguir. No final do terceiro período, um aluno (A) começa a guardar seu material e a professora (P) pergunta: P: Oqueéisso, nãotem mais aula? A: Tem, mas de artes einglês. Eu vou embora. P: Maséimportantequetu fiques, são matérias como as outras. A: Émuito chato, vou sair. Outro colega: Ele está sempre fazendo isso, sempre matando aula, sora. Nem liga!

\section{"Soro, vale nota?"}

No meio do primeiro semestre da quinta série, os períodos ainda eram fator de preocupação para os alunos. Existia uma tensão para conseguir terminar as atividades no tempo previsto pelo professor. A partir do momento em que os alunos sentiram-se capazes de dar conta da atividade no tempo estabelecido, come- çaram a dirigir sua atenção para a negociação dos aspectos a serem avaliados. Preocupavam-se com as notas de provas e trabalhos, como indicado na situação que segue.

Os alunos completavam um questionário. Faltando 15 minutos para o final do período, uma aluna perguntou: A: Eseeu não conseguir acabar hoje? P: Tem que acabar hoje. A: Vale nota? P: (Confirmou, com a cabeça, que sim); A: Muito? Quanto? Cinqüenta? Dez? P: Não. Vale cinco - um ponto para cada questão. A: Porque não vale dez? Dois pontos para cada. P: Não. Estou reservando mais pontos para uma surpresinha para vocês. A: Éprova, né? P: (Confirmou que sim). A: Soro, o senhor costuma fazer prova surpresa? P: Não. A: Óbvio, se um trabalhinho assim jáé difícil, imagina se ele faz prova sem avisar!

\section{"Os pais abandonam os filhos nesse momento importante!"}

Os pais, mesmo preocupados em acompanhar os alunos sem ter um professor como referência, preparavam-se para dar mais autonomia para os filhos quanto à vida escolar. É esperado que pais de filhos pré-adolescentes ajam diferentemente do que pais de crianças menores. Há uma preocupação dos pais em não invadir a vida de seus filhos, que começam a tomar conta de si. As práticas da escola, ao mesmo tempo em que valorizam essa atitude, passam a mensagem de que gostariam de ter os pais mais presentes na escola. Os pais mostram-se com vontade de participar da vida dos filhos, mas percebem que atrapalham se ficarem muito presentes na escola. Acabam se afastando, o que não quer dizer que se distanciem dos filhos.

Até a quarta série, os pais eram considerados colaboradores ativos na aprendizagem dos alunos. Seguidamente, reuniões de pais eram convocadas e era solicitada a ajuda dos pais na educação dos filhos. A fala da professora de quarta série, num desses encontros, ilustra essa parceria: "Gostaria de solicitar a ajuda de vocês nos temas que tenho passado para seus filhos. Não éuma ajuda igual a que se dava na primeira série, mas eles estão precisando da supervisão de vocês".

Essa supervisão, solicitada na quarta série, é vista de forma negativa pelos professores de quinta série. Nessa série, poucos professores enviam temas para casa, 
preferindo realizar atividades em sala de aula. A colocação de que "os pais acabam fazendo os temas pelos alunos" indica que o que antes poderia ser visto como ajuda agora atrapalha o crescimento do aluno. Os pais são convidados a assumirem um novo papel na aprendizagem dos filhos. A parceria dos pais aparece, na quinta série, quando são convocados a comparecerem para receber o boletim e entender os motivos que justificam as notas de seu filho.

Os pais, no início do ano, tentavam encontrar uma forma de acompanhar seus filhos ao mesmo tempo em que tentavam permitir que esses se aventurassem no mundo da aprendizagem com maior autonomia. $O$ que definia esses limites, na maioria das vezes, era o relacionamento entre pais e professores. Alguns pais tentavam vir conversar com professores e normalmente eram atendidos. Se os pais queriam informações sobre as opções metodológicas do professor, isso era explicado. Porém, se os pais vinham justificar alguma atitude do aluno (como esquecer um tema ou trabalho), o professor ouvia a justificativa e dizia que iria retomar com o aluno. O que antes era resolvido somente entre professor e pai, agora passa a ter o aluno como personagem principal. Não basta o pai avisar que está ciente, o aluno precisa assumir a responsabilidade por seus atos. Dessa forma, quando os pais percebiam que sua ida na escola não iria resolver o problema, diziam para os filhos retomarem diretamente com os professores, justificando e assumindo seus atos, e acabavam saindo de cena.

Em diversas reuniões de professores se ouviam frases como "A família abandona o aluno nesse momento difícil', indicando que os professores esperavam alguma atitude dos pais. Porém os pais não estão tão despreocupados com seus filhos. A fala de uma mãe "Agora minha filha está na quinta série! Tens que ver como ela está preparada para essa série. Está superbem adaptada!"pode indicar que os pais acompanham os filhos, porém, ao sentirem que os professores querem estimular uma maior autonomia, tentam fazer esse acompanhamento à distância, afastando-se do contato com o professor.

\section{Discussão}

Por meio dessas frases acessamos alguns aspectos da complexidade do cotidiano escolar.
Segundo Morin (2004), a origem epistemológica da palavra complexidade diz respeito "ao que é tecido junto". Portanto existe complexidade "quando os componentes que constituem um todo são inseparáveis e existe um tecido interdependente, interativo e inter-retroativo entre as partes e o todo e entre o todo e as partes" (p.14).

Ao entrar na quinta série, o espaço escolar assume vários significados. A troca de períodos, os pais não sendo os responsáveis pelo aproveitamento dos filhos, e, conseqüentemente, uma maior apropriação do processo de aprendizagem pelos alunos são algumas alterações que compõem esse momento escolar. Essas mudanças se refletem nas práticas compondo novas exigências e novos desafios.

A quinta série não é necessariamente uma série mais difícil, mas uma série na qual alunos e pais são desafiados a corresponderem com expectativas diferentes. O convívio entre alunos e professores com formação específica gera um campo de estranhamento e criação que logo é compreendido e vivenciado pelos personagens da passagem como um campo de desafio e crescimento.

Uma primeira mudança necessária diz respeito aos sentimentos que se relacionam à quinta série. A experiência de dividir o conhecimento em áreas de ensino gera a sensação de que a quinta série exige mais dos alunos e que é preciso um empenho muito maior para superá-la. Os alunos percebem que a brincadeira fica do lado de fora da sala de aula e que o envolvimento e interesse pelo estudo são cobrados como obrigação.

Os sentimentos com relação à escola e à sala de aula passam a ser diferentes. Estuda-se na sala de aula e se brinca fora dela. Na escola, além de se ter aulas, surge o espaço para amigos, namoros e brincadeiras sem a supervisão de um professor. Mudam as relações de poder. Sem o professor em sala de aula é possível criar outras regras de convivência entre os colegas. Os alunos tomam conta de territórios antes inexistentes para eles (como o corredor na hora de troca de períodos).

Os alunos, que sempre puderam perceber pontos positivos e negativos com relação a ter vários professores, percebem que a relação com eles não é tão complicada assim. Os professores procuram desenvolver um determinado conteúdo, e a relação se dá por meio dele. Isso fica mais evidenciado pelo fato de que o professor tem seu nome substituído pela matéria que ministra (sora de matemática, soro de história). 
Leonço (1997) afirma que a vida dos adolescentes na quinta série é uma gangorra oscilante, devido às mudanças de atitudes; a experimentação de alterações de humor e o contato com diferentes professores permitem ao aluno construir novas formas de relação com o conhecimento, sentindo-se responsável por sua ação. Com esse movimento, surge "um sujeito que, pelo menos afetivamente, já começa a demonstrar'reformulações' diante do seu grupo familiar e escolar" (p.294).

No grupo de professores se identificam concepções diferentes de aprendizagem ao compararmos o grupo responsável pela quarta série com o grupo responsável pela quinta. Contradições entre os professores sobre como o aluno deve agir capacitam o aluno a encontrar recursos em si para atingir os diferentes objetivos propostos pelos professores. Recursos pessoais que refletem nas atitudes dos pais e dos professores. A professora facilita o acesso ao conteúdo, exige que o aluno compreenda o que está sendo discutido ou estimula a criação, porém não age como a cuidadora do processo. A principal responsabilidade do grupo de professores é com o ensino. 0 aluno já deve possuir uma forma de estudar que permita a aprendizagem (com ou sem o auxílio dos pais).

Medos e angústias que os alunos de quarta série constroem sobre a quinta se alteram no momento em que se dão conta que poderão encontrar formas de viver nessa nova organização escolar. Para os alunos o ingresso na quinta série não configura uma ruptura. Muitos aspectos permanecem iguais e os que mudam são percebidos como esperados e naturais desse momento de escolaridade. Eles citam duas alterações principais: a forma de avaliação e a comparação entre as turmas de quinta série.

A avaliação em grupo (sistemática até a quarta série) perde seu espaço. Há uma preferência por provas (orais ou escritas) que permitem ao professor acompanhar o desenvolvimento de cada aluno. Como não é possível sentar ao lado de cada aluno para ver o que estão aprendendo, a prova permite ao professor saber que pontos retomar e como agir com eles, em particular. O fato de os professores compararem as turmas (por circularem nas três turmas observadas) gerava nos alunos um sentimento de injustiça. Apesar de o professor avaliar individualmente os alunos, na execução da aula, o ritmo era determinado pelo grupo.
Os professores insistiam que os alunos deveriam se responsabilizar por seus estudos, suas notas e seus trabalhos. Esse espaço de autonomia gera tanto a preocupação com a nota quanto a possibilidade de matar as aulas que não despertam interesse.

Essas reformulações podem indicar a necessidade de contato entre professor e pais. A possibilidade dos alunos assumirem as responsabilidades por seus atos pode desencadear um processo no qual os alunos decidem sozinhos que atitudes terão na escola. Assim, os pais não ficam sabendo o que está acontecendo e os professores ficam sem apoio frente às atitudes que estão adotando. Isso desencadeia uma busca por apoio simultaneamente em paradoxo com a mensagem de autonomia dada fortemente pela escola.

Com relação aos pais não foi percebido um movimento de abandono dos filhos, e sim a constituição de um espaço possibilitador de crescimento, de experimentação do novo. Os pais assumem um espaço diferenciado, cuidando do desenvolvimento global do filho. Os papéis de pais e professores ficam mais evidenciados e essa alteração modifica as relações entre estes e os alunos.

\section{Conclusão}

A visibilização de algumas faces do poliedro que compõe a vida escolar de uma instituição específica nos indica que a ruptura entre a quarta e a quinta série, na prática, não é tão evidente assim. Os professores mudam (e talvez daí venha a sensação de perder o controle), constituem um campo mais heterogêneo que se intercala diante dos alunos. Os pais perdem o espaço que vinham assumindo com relação à escola e encontram outras formas de acompanhar seus filhos. Os alunos percebem-se com maior autonomia para encontrar recursos pessoais a fim de corresponder às expectativas de seus professores, pais e amigos.

Sem pretender qualquer generalização, os resultados aqui descritos se referem a uma realidade bem especifica, recortada e delimitada, por se tratar de uma pesquisa qualitativa. Todavia os aspectos levantados, trazendo à tona alguns elementos que marcam a passagem da quarta para a quinta série - que costumam ficar tão invisível, tão acomodados em meio ao turbilhão 
de eventos que acontecem na escola - e traçando alguns registros sobre as marcas que se imprimem nos alunos e, por meio e a partir destes, em seus professores e pais, parecem ser um instrumento valioso para descortinar algo dessa massa quase invisível que concorre para formar a subjetividade dos protagonistas do processo escolar.

Mais uma vez constatam-se a riqueza e a complexidade da escola, sua importância como um dos principais agentes do processo civilizatório e de como são infindáveis as problematizações que podem ser feitas sobre esse campo, trazendo sempre renovadas e insuspeitadas possibilidades de análise e investigação.

\section{Referências}

Bossa, R. (2000). A Passagem da quarta para a quinta série do ensino fundamental na percepção do aluno, de seus pais e de seus professores. Dissertação de mestrado não-publicada, Universidade São Marcos, São Paulo.

Eizirik, M. (1997). Ética e cuidado de si: movimentos da subjetividade. Educação, Subjetividade e Poder, 4 (4), 36-43.

Eizirik, M. (2001). Educação e escola: a aventura institucional. Porto Alegre: AGE.
Foucault, M. (2003). Ditos e escritos: estratégia, poder-saber (Vol.4, pp.338-340). Rio de Janeiro: Forense Universitária.

Leite, S. (1993). A passagem para a quinta série: um projeto de intervenção. Caderno de Pesquisa, 84, 31-42.

Leonço, V. C. (1997). Séries Intermediárias: o aluno em transição. Ciências e Letras, 20, 291-298.

Morin, E. (2004). A cabeça bem feita: repensar a reforma, reformar o pensamento (9a ed.). Rio de Janeiro: Bertrand Brasil.

Neves, M., \& Almeida, S. (1996). O fracasso escolar na quinta série, na perspectiva de alunos repetentes, seus pais e professores. Psicologia: Teoria e Pesquisa, 12 (2), 147-156.

Rangel, Z. A. (2001). O processo de transição da unidocência para a pluridocência em classes de quarta para aquinta série do ensino fundamental: olhando a realidade e apontando caminhos. Dissertação de mestrado não-publicada, Pontifícia Universidade Católica do Rio Grande do Sul, Porto Alegre.

Rosa, D., \& Proença, E. (2003). A passagem da quarta para a quinta série: rupturas no sistema educativo e possibilidades de intervenção. In Maraschin; Freitas \& Carvalho (Orgs.), Psicologia e Educação: multiversos sentidos, olhares e experiências (pp.213-224). Porto Alegre: UFRGS.

Taylor, S. J., \& Rogdan, R. (1996). Introducción a los métodos cualitativos de investigación. Buenos Aires: Paidós.

Recebido em: 24/1/2005

Versão final reapresentada em: 1/9/2005

Aprovado em: 18/10/2005 